TITLE:

\title{
Reevaluation of the offset of the Great Wall associated with the ca. M 8.0 Pingluo earthquake of 1739 , Yinchuan graben, China
}

\author{
$\operatorname{AUTHOR}(S):$ \\ Lin, Aiming; Rao, Gang; Hu, Jianmin; Gong, \\ Wangbin
}

\section{CITATION:}

Lin, Aiming ... [et al]. Reevaluation of the offset of the Great Wall associated with the ca. M 8.0 Pingluo earthquake of 1739, Yinchuan graben, China. Journal of Seismology 2013, 17(4): 1281-1294

ISSUE DATE:

2013-10

URL:

http://hdl.handle.net/2433/193053

\section{RIGHT:}

The final publication is available at Springer via http://dx.doi.org/10.1007/s10950-0139391-2:; この論文は出版社版でありません。引用の際には出版社版をご確認ご利用くだ さい。; This is not the published version. Please cite only the published version. 
Reevaluation of the offset of the Great Wall caused by the ca. M

\title{
8.0 Pingluo earthquake of 1739, Yinchuan graben, China
}

\author{
Aiming Lin ${ }^{1 *}$, Gang Rao ${ }^{1,2}$, Jianmin $\mathrm{Hu}^{3}$, and Wangbing Gong ${ }^{3}$ \\ ${ }^{1}$ Department of Geophysics, Graduate School of Science, \\ Kyoto University, Kyoto 606-8502, Japan \\ ${ }^{2}$ Graduate School of Science and Technology, Shizuoka University,
}

Shizuoka 422-8529, Japan

${ }^{3}$ Institute of Geomechanics, Chinese Academy of Geological Science,

Beijing 100081, China

*Corresponding author:

Department of Geophysics

Graduate School of Science

Kyoto University, 606-8502 Kyoto, Japan

E-mail: slin@kugi.kuyoto-u.ac.jp 


\section{Introduction}

The study of large-magnitude earthquakes that occurred prior to the

availability of routine instrumental measurements relies mainly on the analysis of

historical documents and field observations. Significant uncertainties often exist

in relation to the location of the epicenter, the magnitude, and the actual extent of

damage, including the number of fatalities, caused by individual historical

earthquakes, because records generally focused on the effects in the restricted

regions that were settled. Field observations of the geologic effects of large

historical earthquakes provide direct evidence of the coseismic ground

deformation and seismic intensity of these large-magnitude events, and can

therefore help to improve our understanding of the dynamic mechanisms

associated with seismic faulting, and our ability to assess seismic hazards in

densely populated epicentral regions. The ruins of ancient civilizations that

experienced and were damaged by earthquakes are often used as surface

indicators in the study of past seismic events in regions with long historical

records, such as China and Japan (Sangawa, 1986; EBASP, 1998; People 
Network, 2012). For example, historical records and ground deformation features show that the Ojin Emperor Tomb (the Kondayama Tumulus), built in 400-500 AD in Japan, was vertically offset by approximately $1 \mathrm{~m}$ by a large-magnitude earthquake thought to be related to the 1591 M 7.1 Eishou earthquake (Sangawa, 1986).

China is located in one of the most active seismic regions of the world and has experienced numerous destructive earthquakes over its long history. The damage caused by previous large-magnitude earthquakes has been recorded in historical documents, and coseismic ground deformation is locally preserved in ruined ancient buildings such as temples, tombs, and other constructions erected over the past several thousand years (EBASP, 1998; People Network, 2012). Therefore, the ruins of ancient civilizations can sometimes be used to indicate the nature and extent of ground deformation and damage caused by large-magnitude earthquakes.

Previous studies have shown that the Great Wall of China was damaged and offset by the ca. M 8 Pingluo earthquake of 1739 along an active 
fault zone in the Yinchuan graben, on the western margin of the Ordos Block in

northern central China (Fig. 1) (He, 1982; Liao and Pan, 1982; Deng et al., 1984, 1996; Zhang et al., 1986). Based on the apparent displacement, it was concluded that the Great Wall was right laterally offset by $1.45-1.95 \mathrm{~m}$, with a $0.9-2.0 \mathrm{~m}$ vertical component, at three locations in this area (He, 1982; Liao and Pan, 1982; Zhang et al., 1986); consequently, the maximum cumulative displacement of the wall was calculated to be $3 \mathrm{~m}$ dextral and $2.7 \mathrm{~m}$ vertical (Zhang et al., 1986).

However, our recent fieldwork has shown that the Great Wall was probably not affected by the ca. M 8 Pingluo earthquake of 1739, as reported previously, but was actually built on preexisting active fault scarps. This study reinterprets the offset of the Great Wall on the basis of these new field observations, and attempts to identify the source seismogenic fault that triggered the 1739 Pingluo earthquake.

\section{Geologic Setting}

The study region is located in the northern section of the Yinchuan 
graben, on the western margin of the Ordos Block in northern central China (Fig.

1). The Yinchuan graben is elongate in form, being approximately $150 \mathrm{~km}$ long

and $50-55 \mathrm{~km}$ wide, and is bounded by the NNE-SSW trending Helan-Shan

mountain range to the west and the Ordos Block to the east (Fig. 1). Geologic

and seismic reflection data show that the graben contains more than $7000 \mathrm{~m}$ of

Tertiary sediments, and around 1200-1400 m of unconsolidated Quaternary

sediments, indicating a long period of subsidence in an extensional tectonic

environment (Feng et al., 2011). The Yellow River flows SW-NE along the

boundary between the graben and the Ordos Block (Fig. 1). The main active

faults that have developed in the graben strike NNE-SSW, parallel to the

orientation of graben, and include (from east to west) the Huanghe (Huanghe

means Yellow River in Chinese), Yinchuan-Pingluo, Luhuatai, and Helan-Shan

Piedmont faults. Seismic reflection profiles show that the Huanghe Fault is the

main fault that forms the eastern boundary of the graben, and that the Helan-Shan

Piedmont Fault (which runs along the eastern margin of the Helan-Shan

Mountains) forms the western boundary of the graben (Fang et al., 2009; Feng et 
al., 2011).

The Pingluo earthquake (ca. M 8) occurred within the Yinchuan

graben on 3 January 1739, and killed more than 50,000 people (Zhang et al., 1986; Bai et al., 2005). Based on the damage and ground deformation features recorded in historical documents, the strongest ground motion caused by this earthquake seems to have been concentrated in the narrow zone between the Huanghe and Yinchuan-Pingluo faults on the eastern side of the Yinchuan graben, where seismic intensities of up to X-XI (on the Chinese XII seismic intensity scale, Fig. 1b) have been estimated.

\section{Relationship between the Great Wall and active faults}

\subsection{Previous work}

The section of the Great Wall in the study region was built in $1531 \mathrm{AD}$

(Zhang et al., 1986) on the eastern side of the Helan-Shan Mountains, and is found mostly on alluvial fans that tilt E-SE. The wall generally strikes NW-SE $\left(\mathrm{N} 40^{\circ} \mathrm{W}\right)$, and is around $3.5 \mathrm{~km}$ long in the study area (Figs $\left.1-3\right)$. The wall is 
composed mainly of tamped earth (layered adobe), which contains pebbles and

cobbles in the eastern segment, but was made partly from stone, including faced

dimension stone and boulders, in the western segment bounded by the

Helan-Shan Mountains.

In the study area, the Helan-Shan Piedmont Fault principally comprises

three branch faults along which fault scarps, 2-6 m high (F1-F3), have

developed (Figs 2 and 3; Zhang et al., 1986). The F1 and F2 fault scarps face

southeast, while the F3 fault scarp faces northwest to form a small graben

structure between the three scarps (Figs 2 and 3b). The Great Wall has collapsed

where it crosses these three fault scarps, as described below.

A survey team from the Chinese Academy of Sciences was the first to suggest (in 1965) that the base of the collapsed Great Wall was offset by the ca. M 8 Pingluo earthquake of 1739 at three locations across the fault scarps (Figs 2 and 3; He, 1982; Zhang et al., 1986). Subsequently, the details related to the apparent displacement of the Great Wall have been cited and described by many researchers (He, 1982; Liao and Pan, 1982; Deng et al., 1984, 1985, 1996; Zhang 
et al., 1986). The apparent offset of the Great Wall reported in the previous studies at the three locations (Loc. 1-3) was mainly based on the following observations and interpretations.

1) Based on the current state of the Great Wall, the apparent displacement amounts at the three locations were estimated to be around $0.9-0.95 \mathrm{~m}$ vertically at Loc. 1, 1.5-1.9 m vertically and 1.4-1.95 m right laterally at Loc. 2, and 0.1-0.2 m vertically and 0.1-0.2 m left laterally at Loc. 3 (Liao and Pan, 1982; Zhang et al., 1986). The maximum cumulative displacement of the Great Wall was calculated to be $2.7 \mathrm{~m}$ vertically and $3 \mathrm{~m}$ right laterally (Zhang et al., 1986).

2) The Great Wall shows a curved shape in vertical profiles, suggesting that coseismic dragging accompanied the normal faulting on both sides of the fault scarps (He, 1982, Liao and Pan, 1982).

3) The right lateral deflection of some gullies developed on the alluvial fans suggests displacement with a dextral sense of movement, which is probably related to the apparent right lateral offset of the Great Wall (He, 1982). 4) Trench excavations revealed that the faults cutting the alluvial deposits occur 
just under the fault scarps on which the Great Wall lies, suggesting that the apparent offset of the Great Wall was caused by faulting after the construction of the wall along the fault scarps (Liao and Pan, 1982; Deng et al., 1996).

\subsection{In situ observations of the Great Wall}

As part of the current research into active faults and paleoseismicity in the Yinchuan graben, and to further investigate the previous findings outlined above, field visits were made to the Great Wall in an attempt to determine the relationship between the offset of the Great Wall and the active faults. These new field observations (outlined below) cast doubt on the cause and extent of the offset of the Great Wall reported previously at all three locations (Loc. 1-3).

\subsubsection{Loc. 1}

At Loc. 1, the Great Wall is composed mainly of stone, including faced

dimension stone and boulders (Figs 4 and 5), and was reconstructed during the early 1980 s based on the premise that the wall was displaced vertically and 
horizontally (Fig. 5) (He, 1982; Liao and Pan, 1982; Hujita, 1984). Although the reconstructed wall on both sides of the fault scarp has partially collapsed, the location of the wall can be deduced from the remaining material. The wall has a rectangular trapezoidal shape and is $4 \mathrm{~m}$ wide at the base, $3.5 \mathrm{~m}$ wide at the top surface, $12 \mathrm{~m}$ long, and $2.4 \mathrm{~m}$ high on the northwestern side of the supposed fault, and is the same width but only $6.5 \mathrm{~m}$ long and $1.6 \mathrm{~m}$ high on the southeastern side of the supposed fault (Fig. 6a and b). The height difference of the top of the wall, and apparent right-lateral offset measured from the current remnants of the wall across the supposed fault are around 0.8 and $1.2 \mathrm{~m}$, respectively (Fig. 6).

\subsubsection{Loc. 2}

At Loc. 2, the Great Wall lies on the fault scarp, which is around $4 \mathrm{~m}$ high, and is made of tamped earth (layered adobe) containing pebbles and cobbles (Figs 7-9). On the fault scarp, the wall has collapsed, and a gap of around 4 m wide has formed. A sketch (Fig. 9) based on field measurements shows that the wall is $3.5 \mathrm{~m}$ high, $3.5 \mathrm{~m}$ wide at its base, and $1.5 \mathrm{~m}$ wide at the 
top on the uplift (northwestern) side of the fault scarp, but $1.9 \mathrm{~m}$ high, and 2 and $1.35 \mathrm{~m}$ wide at the base and top surface of the wall, respectively. The height of the wall is almost the same on both sides of the fault scarp, but there is a height difference of $1.6 \mathrm{~m}$ between the top surfaces of the currently remaining parts of the wall on either side of the gap on the fault scarp (Figs 7 and 9). The layering structure of the tamped earth of the wall is tilted to the southeast, generally parallel to the topographic surface of the fault scarp (Fig. 7).

\subsubsection{Loc. 3}

At Loc. 3, the Great Wall is situated on an alluvial fan and was built along a gully that strikes NNW-SSE (Figs $2 \mathrm{~b}$ and 10). The wall is made of tamped earth containing pebbles and cobbles, and has collapsed and been eroded, causing a gap 3-5 m wide to form (Fig. 10a and b). A distinct fault scarp, striking NNE-SSW, 0.5-2.0 $\mathrm{m}$ high, and facing northwest towards the Helan-Shan Mountains (antithetic to the fault scarps observed at Loc. 2 and 3), developed on both sides of the gully, but the lowest terrace bounded by the gully 
channel where the wall is situated was not deformed. The top surface and base of the Great wall are continuous and linear, with no distinct vertical or horizontal displacement (Fig. 10a and b).

\section{Discussion}

\subsection{Offset of the Great Wall}

As stated above, the Great Wall running along the fault scarps has

collapsed at three locations. Previous studies reported that the Great Wall was

displaced by the ca. M 8 earthquake of 1739 (He, 1982; Liao and Pan, 1982;

Deng and You 1985; Zhang et al., 1986); however, new field observations and measurements made here show that the Great Wall actually sits on the preexisting fault scarp, and was not offset at these three locations following its construction; this hypothesis is discussed in detail below.

At Loc. 1, previous studies reported that the wall was offset by $1.2-1.45 \mathrm{~m}$ right laterally and $0.35-0.9 \mathrm{~m}$ vertically (Liao and Pan, 1982; Zhang et al., 1986), based on measurements of the current state of the wall (Fig. 4b). As 
shown in the sketches (Figs 5 and 6), the Great Wall was reconstructed in a rectangular trapezoidal shape during the early 1980s based on the assumption that the wall was displaced by the ca. M 8 earthquake of 1739 (Figs 5 and 6). However, it is clear that the reconstructed parts of the wall have an unnatural shape and are around 1.0-1.2 m wider than the adjacent wall, and asymmetric in shape to both sides of the central line of the adjacent wall (Fig. 6a and b). The central line of the original wall, on both sides of the supposed fault, is continuous and linear. This indicates that at this site, the original wall followed a straight line, and had not been offset since its construction.

Furthermore, the fault scarp on which the wall sits is about $2 \mathrm{~m}$ high (Fig. 6c), which is $1 \mathrm{~m}$ higher than the apparent vertical displacement of the wall. This indicates that the fault scarp pre-dates construction of the wall. Away from the supposed fault, the wall on both sides is about $2 \mathrm{~m}$ high (Fig. 6c). If the top of the wall was restored so as to follow the underlying topographical slope, it would show a curved shape, and follow the fault scarp with no distinct vertical displacement. This suggests that the current $0.9 \mathrm{~m}$ vertical step in the wall was 
made artificially during the reconstruction at Loc. 1, based on the assumption that the wall was offset both right laterally and vertically.

The maximum apparent right lateral and vertical displacement of the Great Wall at Loc. 2 were estimated to be around $0.95-2.0 \mathrm{~m}$ vertically (Liao and Pan, 1982; Deng et al., 1984; Zhang et al., 1986) and $1.67 \mathrm{~m}$ right laterally (Zhang et al., 1986). The vertical offset was measured directly by examining the top surface of the wall on each side of the fault scarp, as shown in Fig. 8a (from figure 11 in Zhang et al., 1986). It is clear that the top surface of the wall on the downthrown side of the fault scarp has been eroded and undermined, and is consequently lower than other sections farther from the fault scarp. As shown in Fig. 7, the layered structures in the tamped earth of the wall are generally parallel to the topographic surface along the wall. These layered structures formed as a result of the tamping of earth with rectangular wooden frames during construction (a method commonly used to construct earthen houses in China). If the layered structures are extended along their curved lines, the wall can be smoothly connected with continuous layering that runs parallel to the 
topographic surface of the fault scarp and with no distinct vertical offset of the top surface of the wall (Figs 7a and 9a).

In plan view, the wall on the fault scarp shows a rectangular outline that is $3.5 \mathrm{~m}$ wide; i.e., about $1-2 \mathrm{~m}$ wider than the top of the wall farther away from the supposed fault (Fig. 9b). This rectangular shape is probably a beacon stand (Fig. 8c); such stands were generally built on topographical highpoints of the Great Wall to hold signal fires (Fig. 2a). The distance between the base of the beacon stand on the uplift side, and the top of the wall on the downside was about $1.2 \mathrm{~m}$ (Fig. 8d). However, the whole wall across the fault scarp at this site is linear with no horizontal offset (Fig. $7 \mathrm{~b}$ and c), and the central line of the top wall surface is also linear, with no distinct horizontal offset (Fig. 9b). This suggests that the right lateral displacement of $1.67 \mathrm{~m}$ reported by Zhang et al. (1986) was measured between the base and top of the wall on the fault scarp (Fig. $8 \mathrm{~d})$, which is not an actual offset. Consequently, it appears that the wall is neither vertically nor horizontally displaced at Loc. 2.

Previous studies reported that the wall was offset by around $0.1-0.2 \mathrm{~m}$ 
both vertically and right laterally at Loc. 3 (Liao and Pan, 1982; Zhang et al., 1986). In fact, these displacements are difficult to measure accurately due to the collapse and erosion of the wall. The new field measurements reported here show that both the central line and baseline of the wall on both sides of the supposed fault are linear and continuous, with no distinct offset either vertically or horizontally (Fig. 10c). As stated above, the wall at this site was constructed in a small gully, where no fault scarp is recognizable, on the lowest terraces bounded by the gully channel, although a $0.5-2.0 \mathrm{~m}$ high fault scarp is evident on both sides of the gulley. This indicates that no faulting event occurred here after the formation of the lowest terraces. These observations confirm that the Great Wall was not offset at this location after its construction.

The above evidence supports the conclusion that the Great Wall was not disturbed by faulting at any of the three locations studied here.

\subsection{Seismogenic fault of the 1739 ca. M 8 Pingluo earthquake}

The apparent offset of the Great Wall has been widely used in previous 
studies as the sole piece of evidence in support of the proposal that the ca. M 8 earthquake of 1739 was triggered by the Helan-Shan Piedmont Fault (He, 1982; Liao and Pan, 1982; Deng et al., 1984; Zhang et al., 1986). Based on this ambiguous evidence, many previous studies have documented the neotectonic features and dynamic characteristics of active faults, and assessed the scale of the seismic hazard, in the Yinchuan graben (Li and Wan, 1982; Liao et al., 1982; Zhang et al., 1982; Den et al., 1984, 1996; Xie et al., 2000, Zhao et al., 2007; Yang et al., 2009). However, to date, there is no other geological or seismic evidence that the Helan-Shan Piedmont Fault is the seismogenic fault that caused the 1739 earthquake.

As shown above, the Great Wall is not offset by faulting along the Helan-Shan Piedmont Fault; therefore, this fault is probably not the source seismogenic fault of the 1739 Pingluo earthquake. Based on historical records, the intensity of the 1739 earthquake in the Yinchuan graben can be inferred as shown in Fig. 1 (Zhang et al., 1986; Bai et al., 2005). The strongest intensity, of up to X-XI (on the Chinese XII seismic intensity scale) is distributed along the 
Yinchuan-Pingluo Fault (Bai et al., 2005; China Earthquake Network Center,

2012). Historical records made within three weeks of the 1739 earthquake

document that in the intensity X-XI zone, buildings were almost completely

destroyed and most people died, and the intense ground deformation included

subsidence of 2-3 m over a wide area, liquefaction, and numerous surface

fissures (Bai et al., 2005). In contrast, the seismic intensity in the Helan-Shan

piedmont area along the Luhuatai and Helan-Shan Piedmont faults was less than

VI-VII, leaving buildings only slightly damaged and resulting in no distinct

ground deformation (Zhang et al., 1986; Bai et al., 2005). These historical

records indicate that the strongest ground motion occurred in the narrow band

that experienced a seismic intensity of between $\mathrm{X}$ and XI along the

Yinchuan-Pingluo Fault.

Recent studies have shown that the greatest seismic intensity, and most

damage, generally occurs within a relatively narrow band along the seismogenic

fault that triggers such large earthquakes; e.g., the 1995 M 7.2 Kobe earthquake

(Shimamoto, 1995), the $1999 \mathrm{M}_{\mathrm{w}}$ 7.6 Taiwan Chi-Chi earthquake (Lin et al., 
2001), and the $2008 \mathrm{M}_{\mathrm{w}}$ 7.9 Wenchuan earthquake (Lin and Ren, 2009; Lin et al.,

2010; Ren and Lin, 2010).

The evidence presented above strongly suggests that the

Yinchuan-Pingluo Fault is the seismogenic fault that triggered the ca. M 8

earthquake of 1739 . However, more work is required if we are to fully

understand the surface deformation features associated with the seismogenic

fault that triggered this event, and so more accurately assess the ongoing seismic

hazard in the densely populated Yinchuan graben.

\section{Summary}

Based on the field investigations completed as part of this study, the

following conclusions can be drawn:

(i) the Great Wall was not offset by the ca. M 8 earthquake of 1739

as previously reported, but the wall was, in fact, built on

existing fault scarps; 
(ii) the Yinchuan-Pingluo Fault was most probably the source seismogenic fault of the 1739 earthquake;

(iii) more work is required if we are to better understand the deformation characteristics of the source seismogenic fault, and also improve our ongoing assessments of the seismic hazard within the densely populated area of the Yinchuan graben.

\section{Acknowledgements}

We are grateful to Y. Lin for drawing the sketches. This work was supported by a Grant-in-Aid Scientific Research (A) (Science Project No. 23253002 for A. Lin) of the Ministry of Education, Culture, Sports, Science and Technology of Japan, and a Research project of China Geological Survey (Project No.1212011120099 for J. Hu). 


\section{References}

Bai, M., and D. Jiao (2005). The historical analysis for $\mathrm{M} \sim 8$ earthquake in 1739 at Yinchuan-Pingluo area. Northwestern Seismological Journal 27, 135-140 (in Chinese with English abstract).

Deng, Q., Y. Wang, Y. Liao, W. Zhang, and M. Li (1984). Colluvial wedges and Holocene active along the range-front fault of Helan Shan. Chinese Science Bulletin 29, 557-560 (in Chinese with English abstract).

Deng, Q., and H. You (1985). Fault scarps research and earthquake risk estimation---example in eastern Helanshan fault scarps. Northwestern Seismological Journal 7, 29-38 (in Chinese with English abstract).

Deng, Q., and Y. Liao (1996). Paleoseismology along the range-front fault of Helan Mountains, north central China. Journal of Geophysical Research 101, 5873-5893.

Editorial Board, Annals of Sichuan Province (EPASP) (1998). Annals of Sichuan Province: annals of earthquake. Sichuan People Press, Chengdu, China, p.382. 
Fang, S., C. Zhao, C. Chai, B. Liu, S. Feng, M. Liu, Q. Lei, and H. Liu (2009).

Seismic evidence of crustal structures in the Yinchuan faulted basin.

Chinese Journal of Geophysics 52, 1768-1775 (in Chinese with English

abstract).

Feng, S., R. Gao, C. Long, S. Fang, C. Zhao, K. Kou, Y. Tan, and H. He (2011).

The compressive stress field of Yinchuan graben: deep seismic reflection

profile. Chinese Journal of Geophysics 54, 692-697 (in Chinese with

English abstract).

He, S. (1982). On the dislocation of the Great Wall near the Shizuishan City,

Nigxia Automous Region, In: The Active Faults in China, 151-153. Beijing, Seismological Press.

Huzita, K. (ed) (1984). Tectonic Belt in Asia_-between the Himalaya and Japan Trench. p.400, Shankaido, Tokyo.

Li, M., and Z. Wan (1984). Characteristics of the earthquake-generating structures for magnitude 8.0 Pingluo earthquake of 1739 and he process of its preparation. Seismology and Geology 6, 23-28 (in Chinese with English 
abstract).

Liao, Y., and Z. Pan (1982). Dislocation of the Great Wall in the Hongguozigou, Ningxia Autonomous Region. Seismology and Geology 4, 77-79 (in Chinese with English abstract).

Liao, Y., Y. Wang, F. Kui, F. Song, and P. Liu (1982). Preliminary study on the range-front fault of Helan Shan. In: The Active Faults in China, p.162-166. Beijing, Seismological Press.

Lin, A., T. Ouchi, A. Chen, and T. Maruyama (2001). Co-seismic displacements, folding and shortening structures along the Chelungpu surface rupture zone occurred during the 1999 Chi-Chi (Taiwan) earthquake. Tectonophysics 330, $225-244$

Lin, A., Ren, Z., 2009. The Great Wenchuan Earthquake of 2008-A

Photographic Atlas of Surface Rupture and Related Disaster. Springer, Berlin, p. 121p (ISBN:978-3-642-03758-0).

Lin, A., Ren, Z., and D. Jia (2010). Co-seismic ground-shortening structures produced by the $2008 \mathrm{M}_{\mathrm{w}} 7.9$ Wenchuan earthquake, China. Tectonophysics 
491, 21-34.

People Network (2012). 79 large historic earthquakes recorded in Chinese

historic documents. http://politics.people.com.cn/GB/80291/7261351.html

(last accessed 30 Oct, 2012).

Ren, Z., and A. Lin (2010). Co-seismic landslides induced by the 2008

Wenchuan magnitude 8.0 earthquak, as revealed by PRISM and AVNIR2

imagery data. International Journal of Remote Sensing 31, 3479-3493.

Sangawa, A. (1986). Fault displacement of the Kondayama Tumulus faused by

earthquake. Zisin, J. Seism. Soc. Japan 39, 15-24 (in Japanese with English abstract).

Shimamoto, T. (1995). Queerness of "the earthquake disaster band". Kagaku 65, 195-198 (in Japanese).

Xie, F., S. Shu, S. Dou, S. Zhang, and X. Cui (2000). Quaternary tectonic stress field in the region of Haiyuan-Liupanshan fault zone to Yinchuan fault-depression. Seismology and Geology 22, 139-146 (in Chinese with English abstract). 
Yang, Z., Y. Duan, F. Wang, J. Zhao, S. Pan, and L. Li (2009). Tomographic determination of the deep earthquake faults in Yinchuan basin by using three-dimensional transmission technology. Chinese Journal Of Geophysics 52, 2026-2034 (in Chinese with English abstract).

Zhang, B., Y. Liao, S. Guo, R. E. Wallace, R. C. Bucknam, and T. C. Hanks (1986). Fault scarps related to the 1739 earthquake and seismicity of the Yinchuan graben, Ningxia Huizu Zizhiqu, China. Bull. Seismo. Soc. Am. $76,1253-1287$.

Zhang, W., Y. Liao, Z. Pan, and F. Song (1982). On the piedmont scarp in alluvial fan of Mt. Helanshan. Seismology and Geology 4, 32-34 (in Chinese with English abstract).

Zhao, W., X. Zhang, J. Sheng, and X. Zeng (2007). Research on seismic risk of segments of each active fault located in Yinchuan Basin. Journal of Natural Disasters 16, 79-83 (in Chinese with English abstract). 


\section{Captions to figures}

Figure 1. (a) Location map and (b) geological map of the study region, showing the geologic structures of the Yinchuan graben (geological map modified from Li and Wan, 1984, and Fang et al., 2009; seismic intensity data from Bai et al., 2005). ATF: Altyn Tagh Fault; HYF: Haiyuan Fault; KLF: Kunlun Fault; QLF: Qinglin Fault; LMSTB: Longmen Shan Thrust Belt.

Figure 2. Google Earth image (a) and the topographical profiles (b) showing the tectonic topography of the Helan-Shan Piedmont Fault and the line of the Great Wall in the study area. Loc. 1-3 denote the three field sites where the Great Wall crosses fault scarps.

Figure 3. The Great Wall in the study area. (a) General view. (b) Close-up of (a). F1-F3 denote the branch faults of the Helan-Shan Piedmont Fault, on which the Great Wall sits. See Fig. 2 for detailed locations of Loc. $1-3$. 
Figure 4. The Great Wall at Loc. 1. (a) General view. (b) The collapsed state of the Great Wall cross the F1 fault scarp at Loc. 1. Note that the Great Wall is composed of faced dimension stone and boulders.

Figure 5. Apparent displacement of the Great Wall at Loc. 1. (a) Reconstructed Great Wall (reconstructed in 1981) showing apparent vertical and horizontal offsets (photograph from Huzita, 1984). (b, c) Apparent offsets of the Great Wall measured in situ: $1.45 \mathrm{~m}$ right laterally and 0.9 m vertically. (d) Longitudinal view of the Great Wall. Note that the central line of the top surface of the Great Wall is linear, with no distinct horizontal displacement.

Figure 6. Sketches showing the geometric shape and in situ measurements of the width and height of the Great Wall at Loc. 1. (a) Perspective view of the Great Wall. (b) In situ measurements of the widths of the top and base of the wall. Note that the central line of the main part of the wall is not offset in the horizontal. 
Figure 7. Photographs showing the apparent vertical displacement of the Great

Wall at Loc. 2. (a) The Great Wall sits on the F2 fault scarp, which has

collapsed and been eroded. (b) A 4-m-wide gap of the wall forms on

the F2 fault scarp. Note that the Great Wall is made of tamped earth

with layered structures (red dotted lines) and the wall height is the

same on both sides of the F2 fault scarp.

Figure 8. The current state of the Great Wall at Loc. 2, looking along the wall

(approximately) to the (a) NW and (b) SE. Note that the central line

of the top surface in (a) and side of the Great Wall are offset in the

horizontal. (c) Close-up view of (a). The central line is straight, with

no distinct horizontal displacement. The Great Wall on the western

side of the gap is rectangular, is higher and wider than the wall on

either side, and resembles a beacon stand as shown in (d) and Figure 9.

(d) In situ measurements along the wall show that the apparent

displacement of the wall is ca. $1.2 \mathrm{~m}$. 
Figure 9. Sketches showing the geometric shape and in situ measurements of the width and height of the Great Wall at Loc. 2. (a) Perspective view of the Great Wall. (b) Width of the top and base of the wall. Note that the central line of the main part of the wall is not offset in the horizontal.

Figure 10. (a) General view of the Great Wall at Loc. 3. Note that the F3 fault scarp (facing northwest) is evident on both sides of the wall and is not vertically offset. (b) Close-up view of (a). (c) Longitudinal view of the Great Wall. Note that both the central line and sides of the Great Wall are not distinctly displaced in the horizontal. 


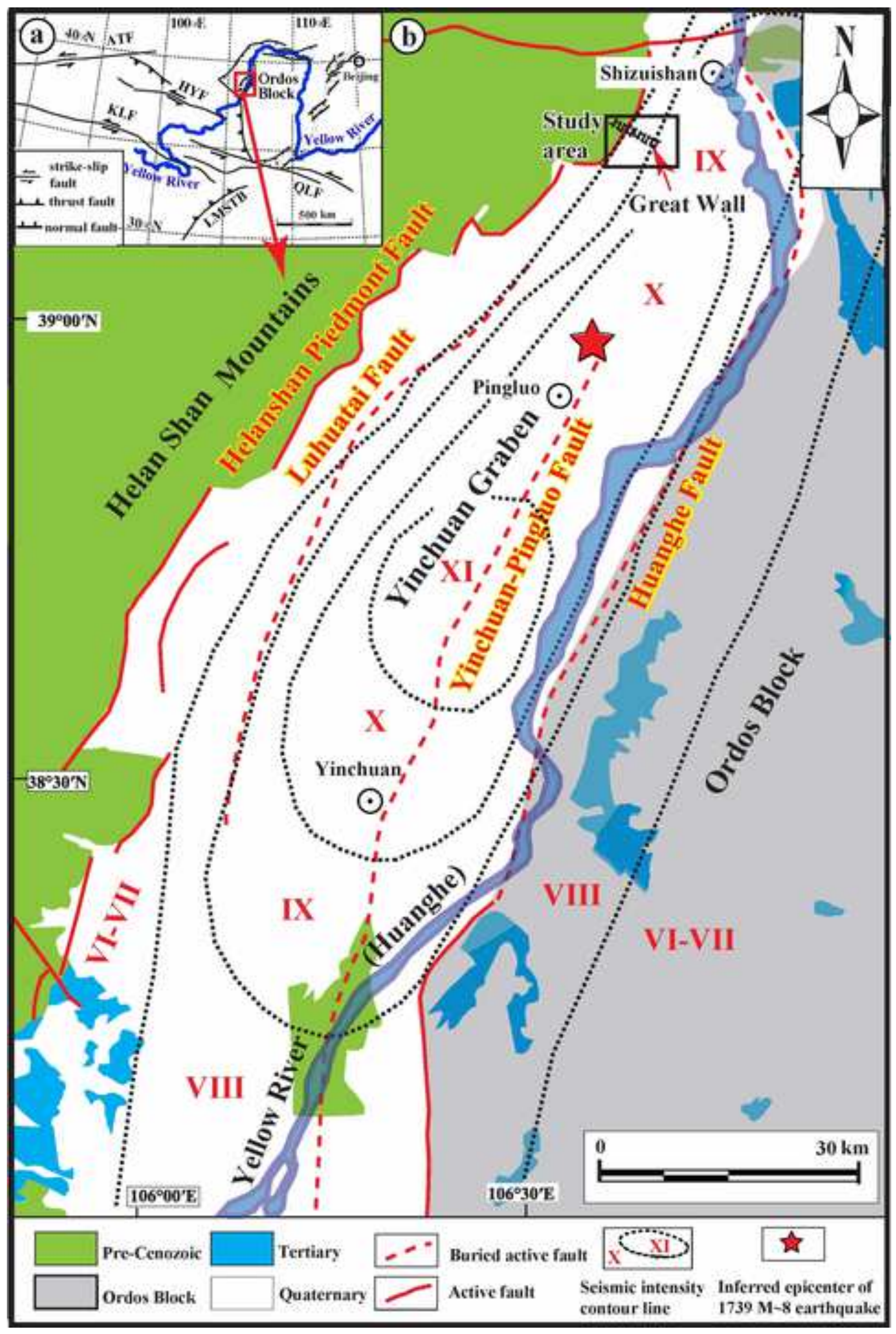




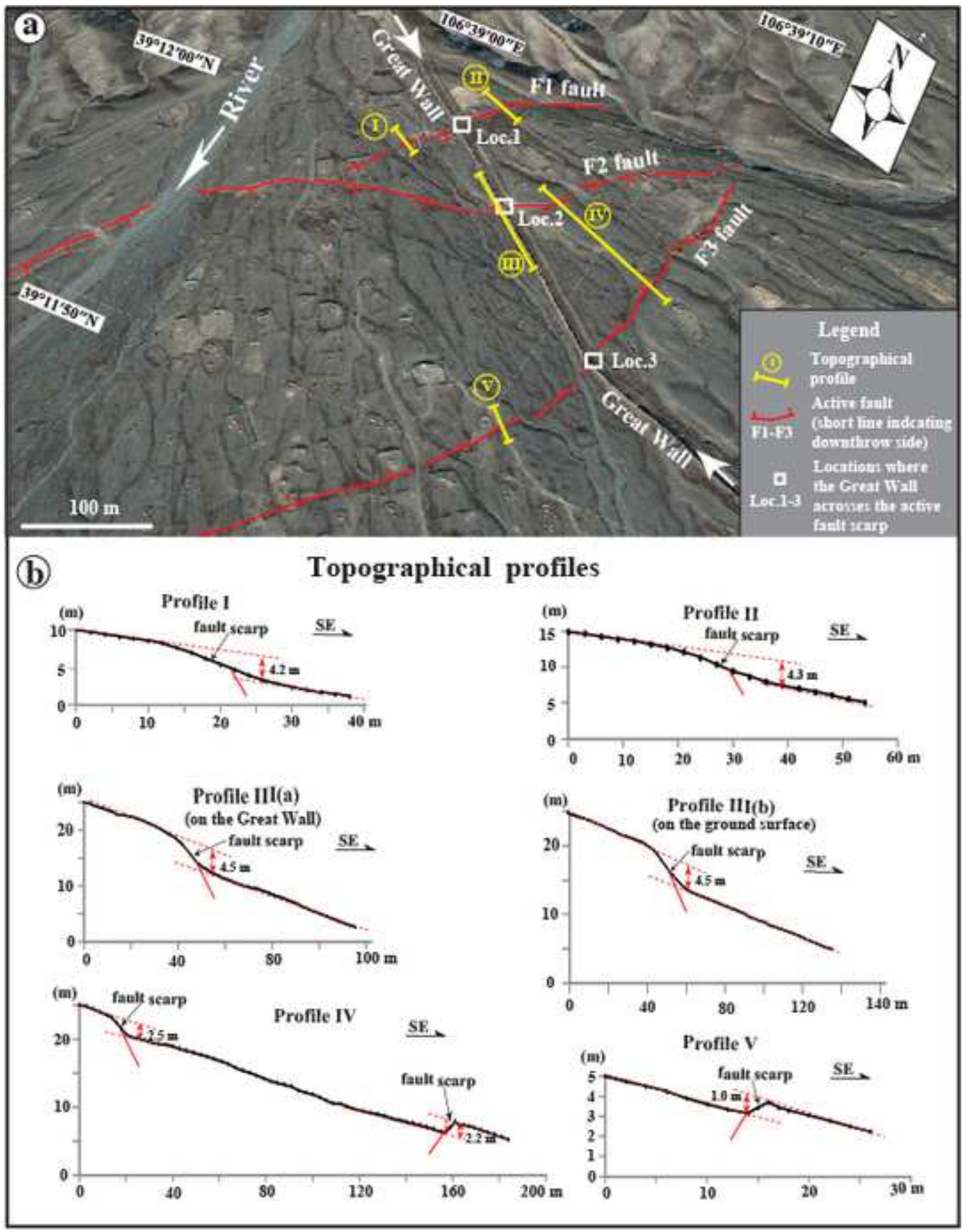


Fis. 都大学

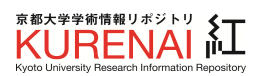
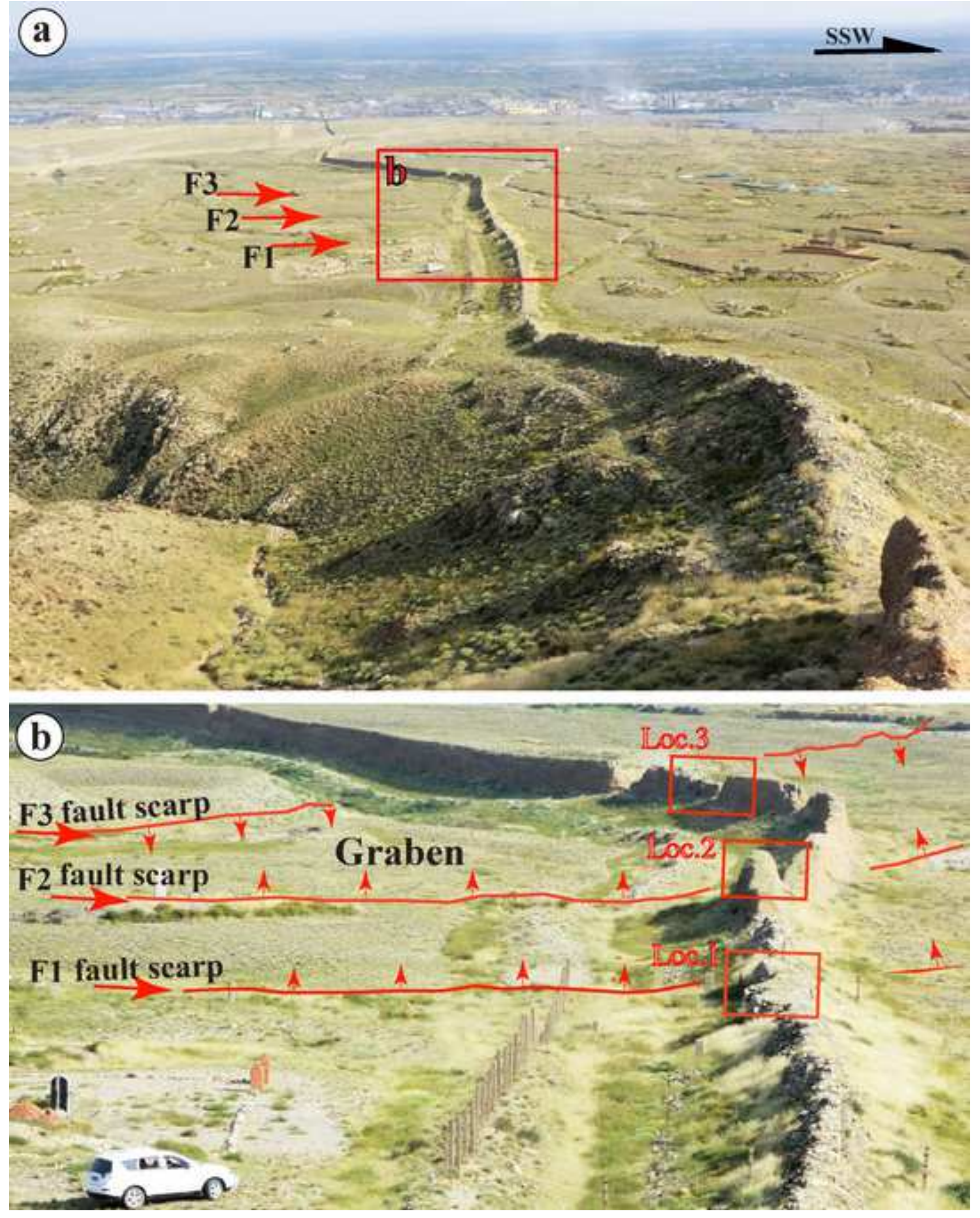


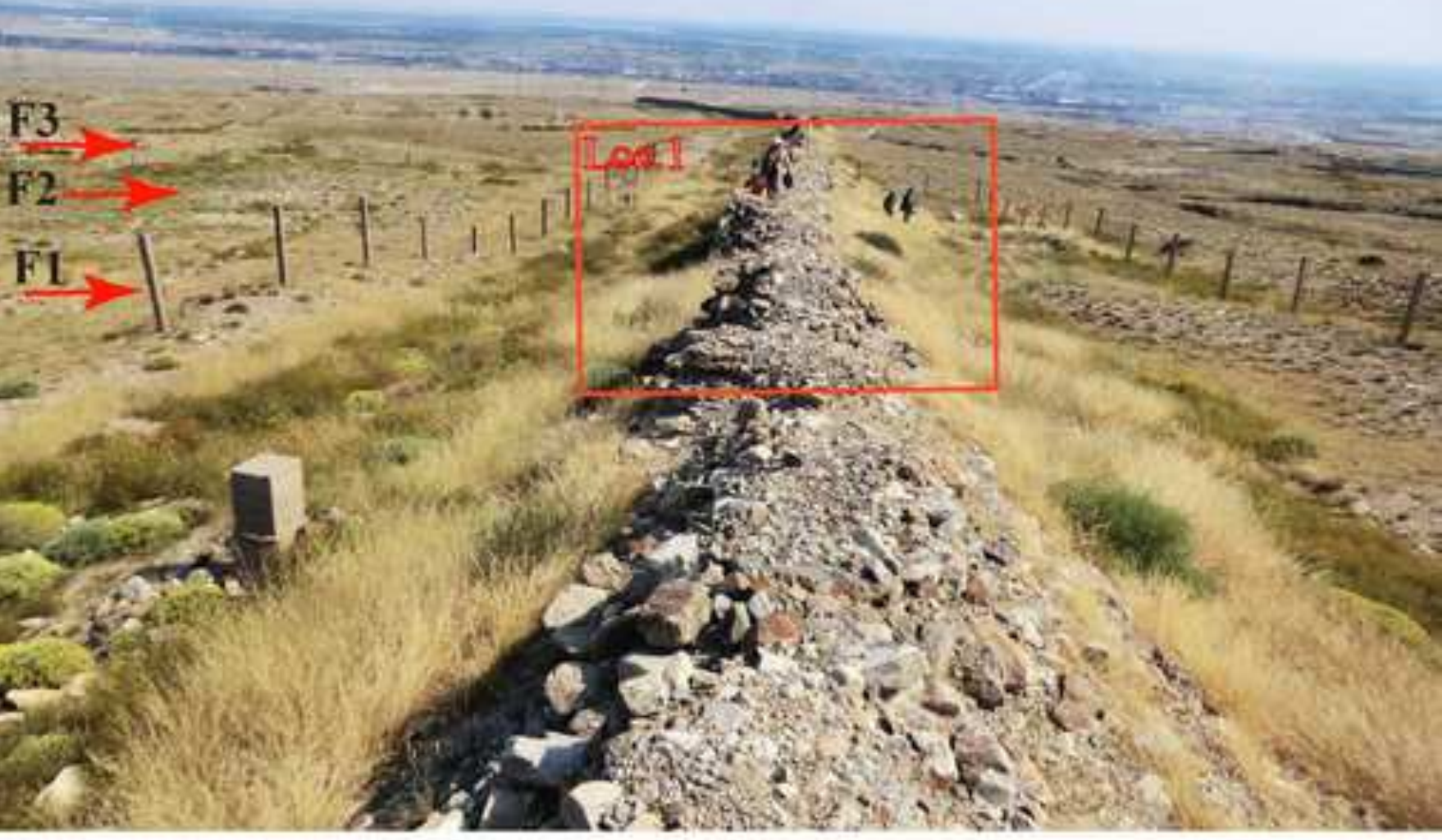

\section{(b)}

$\downarrow$ Beacon stand

\section{NNE}

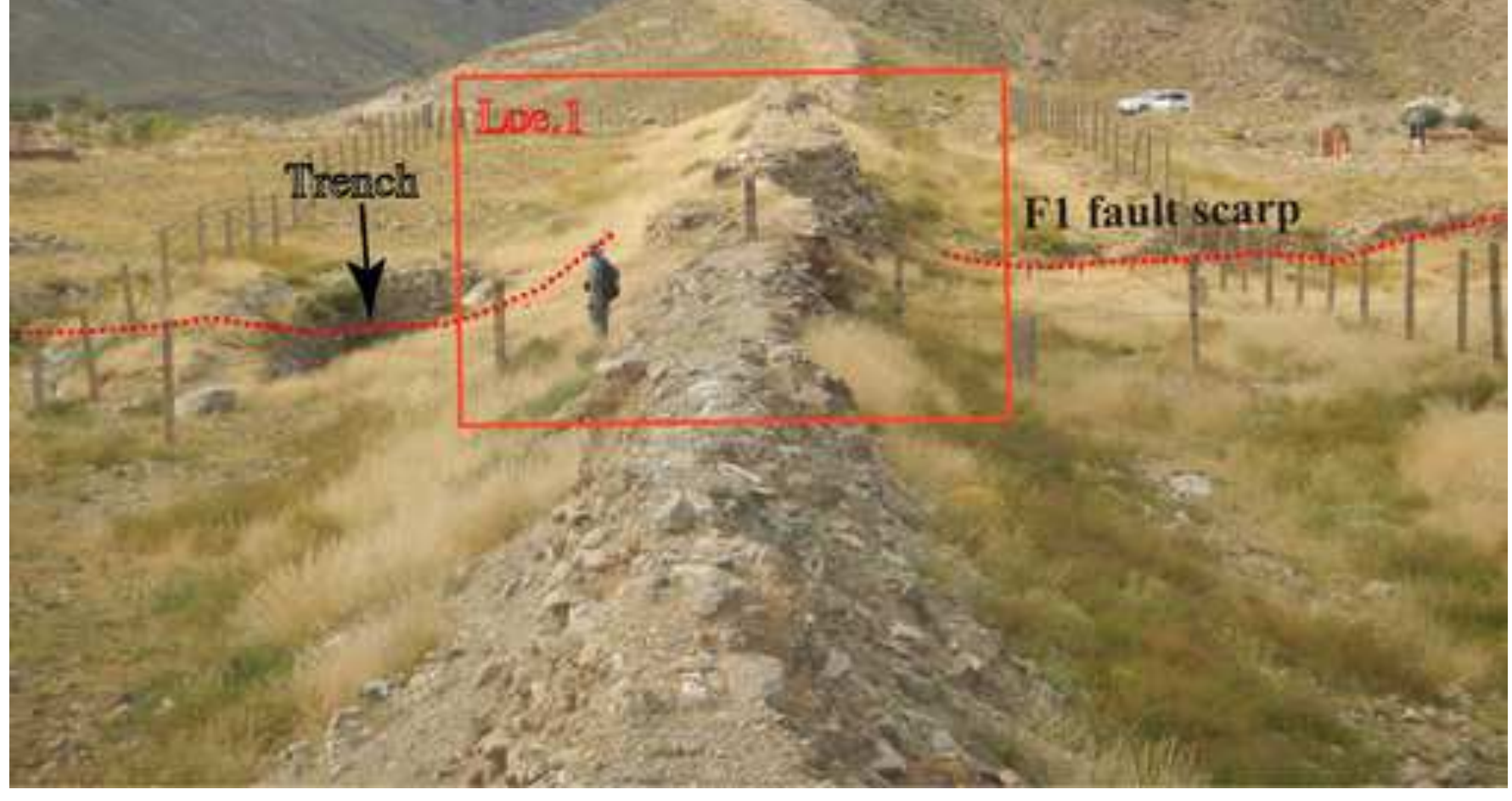


Click here to download high resolution image
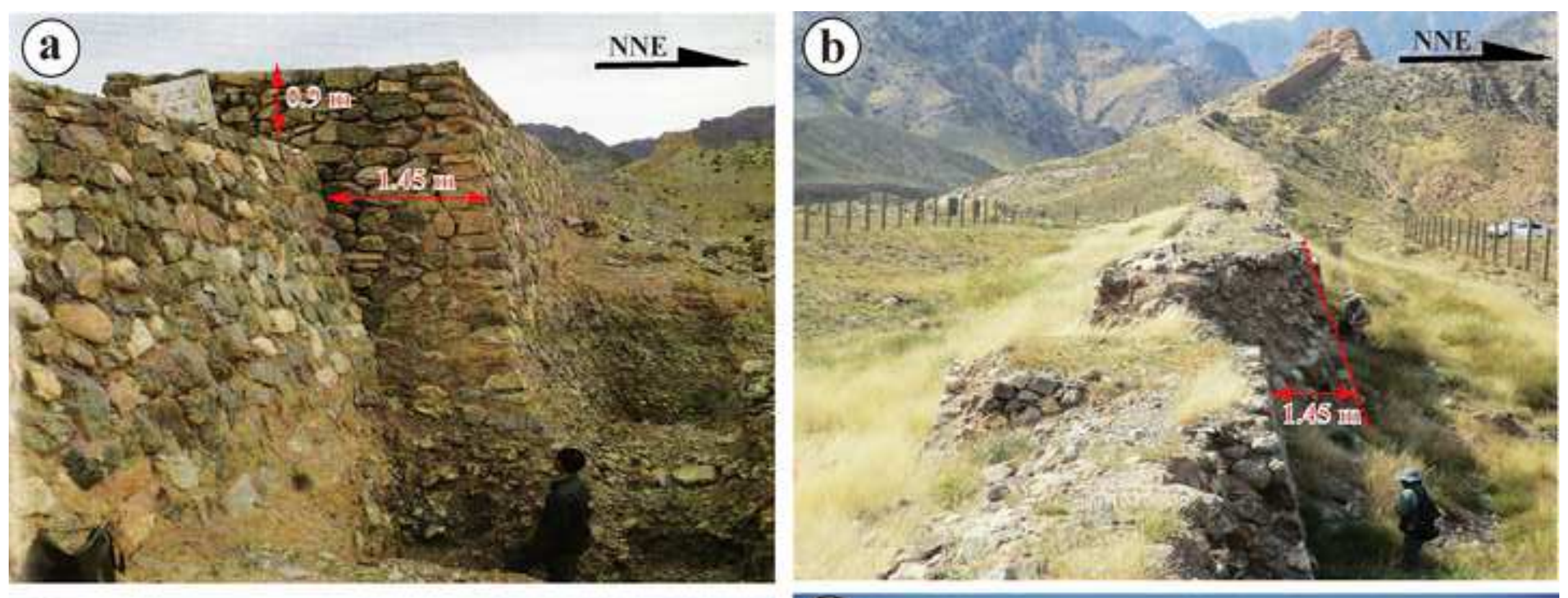

c)

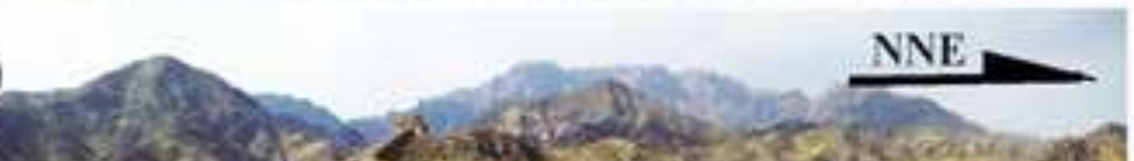

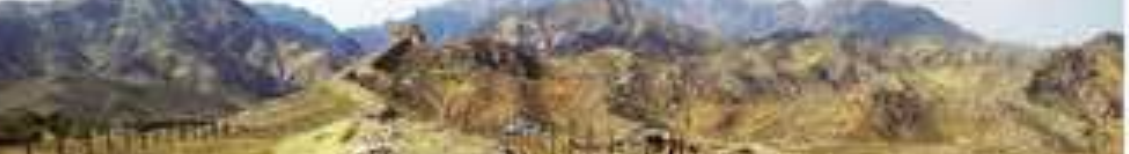
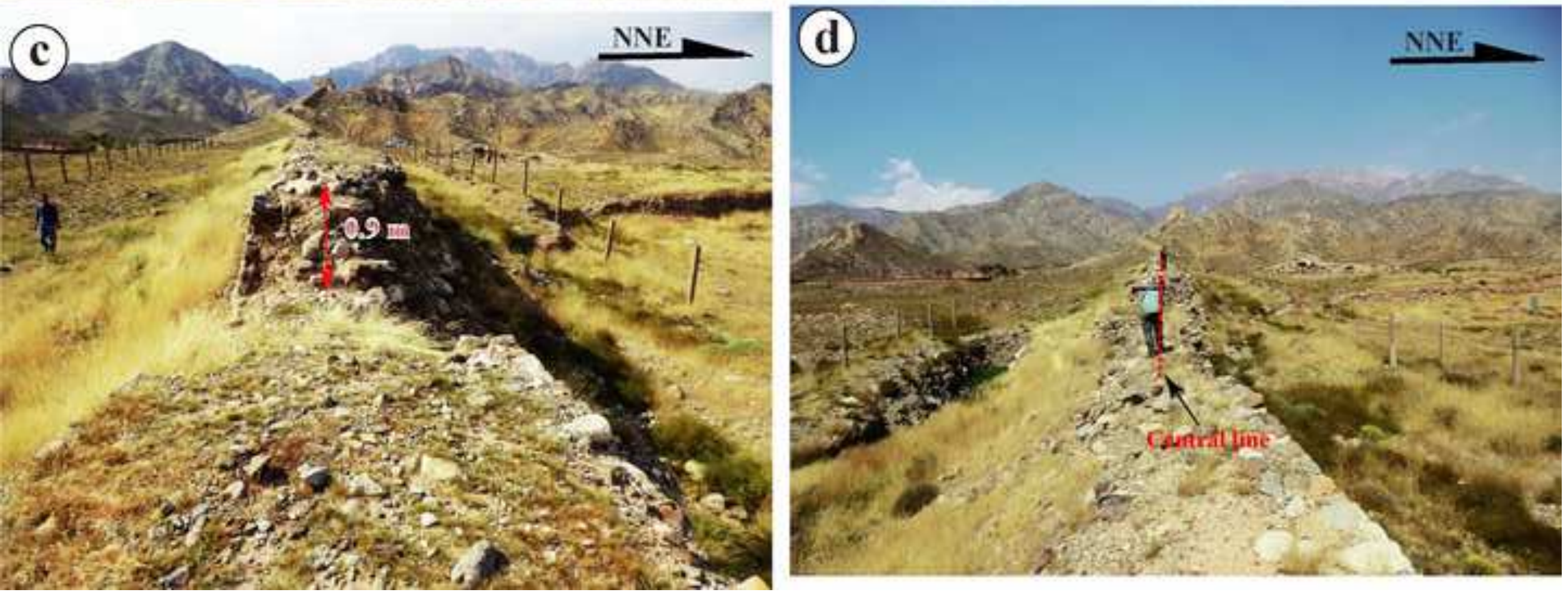


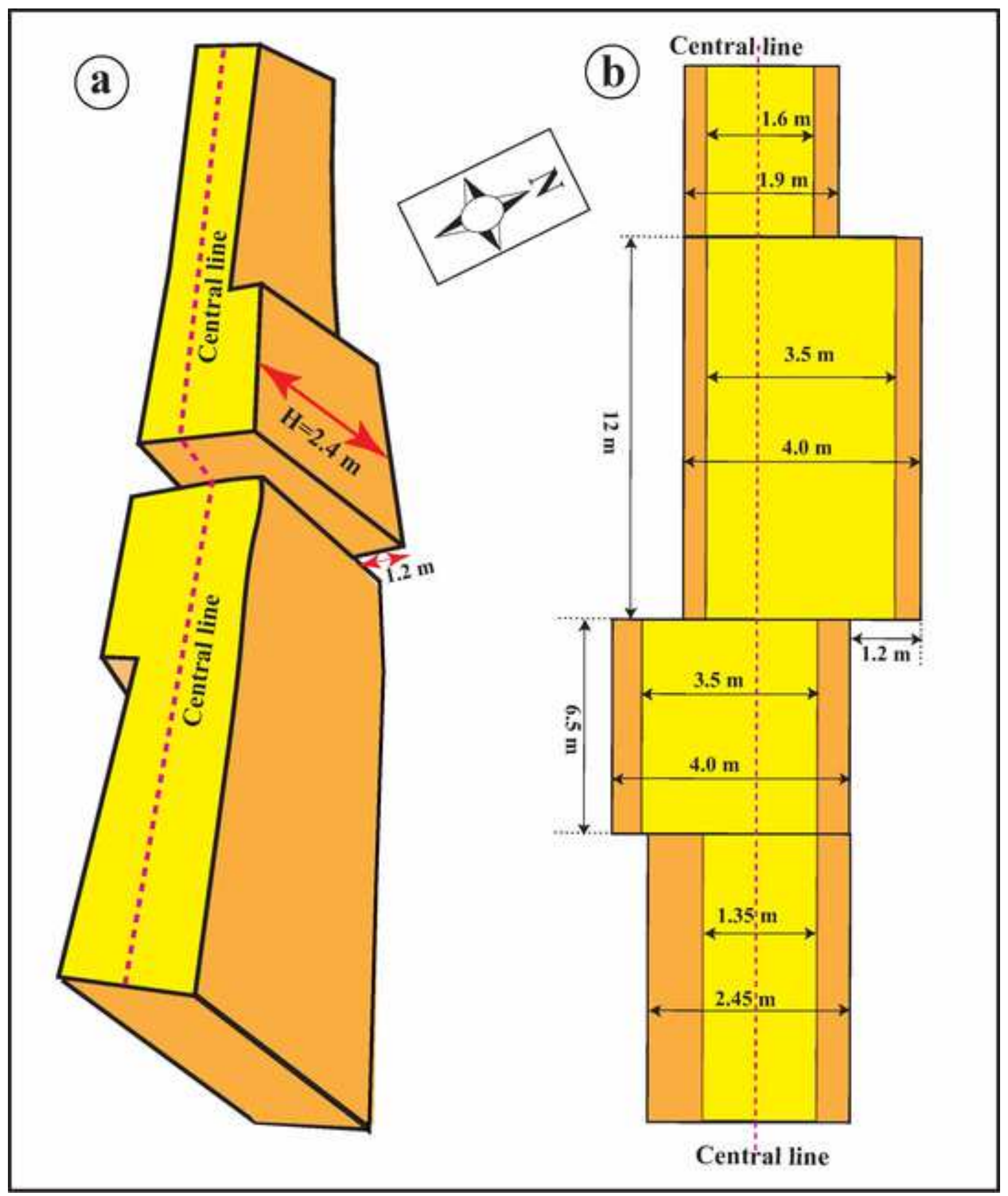


Click here to download high resolution image
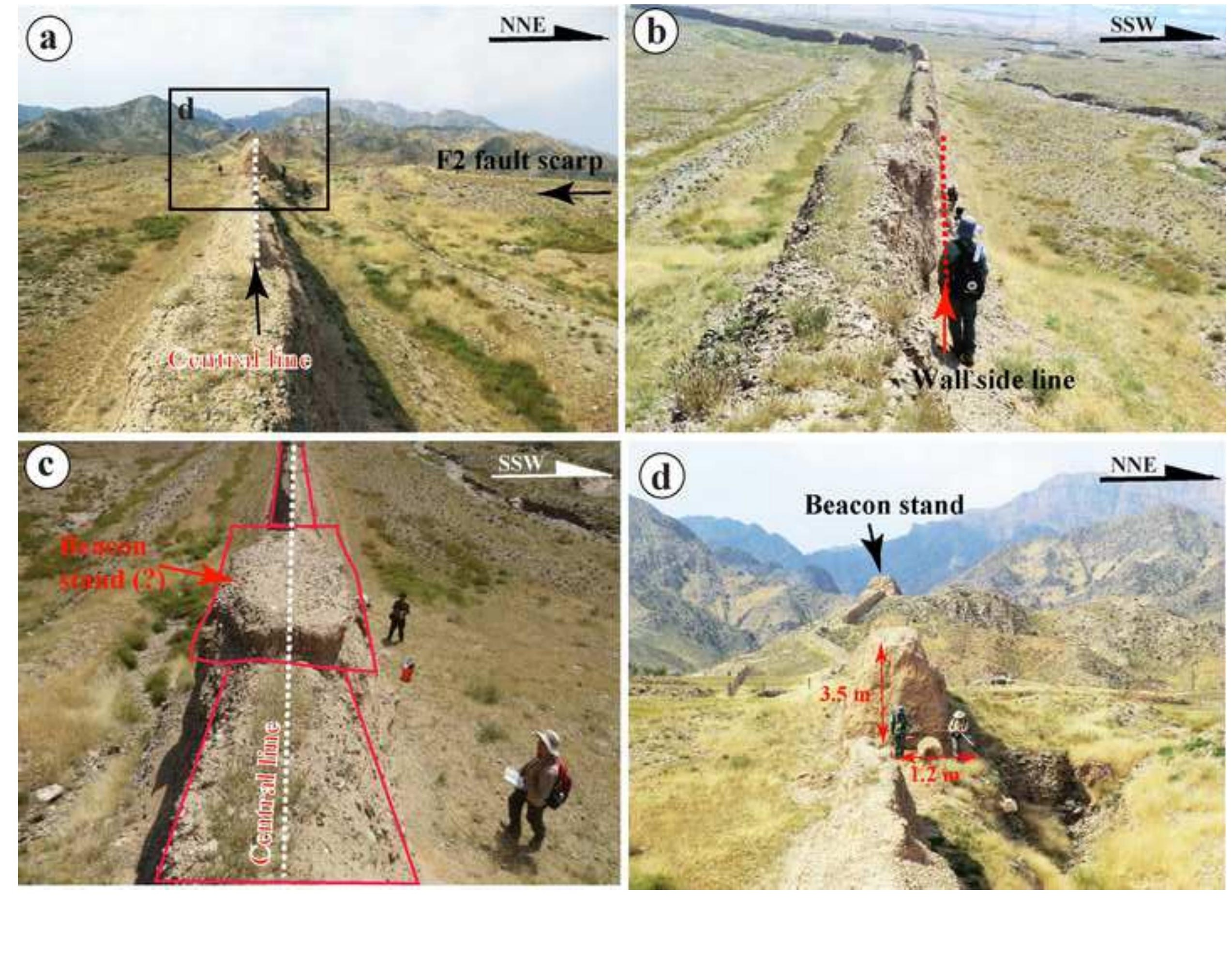


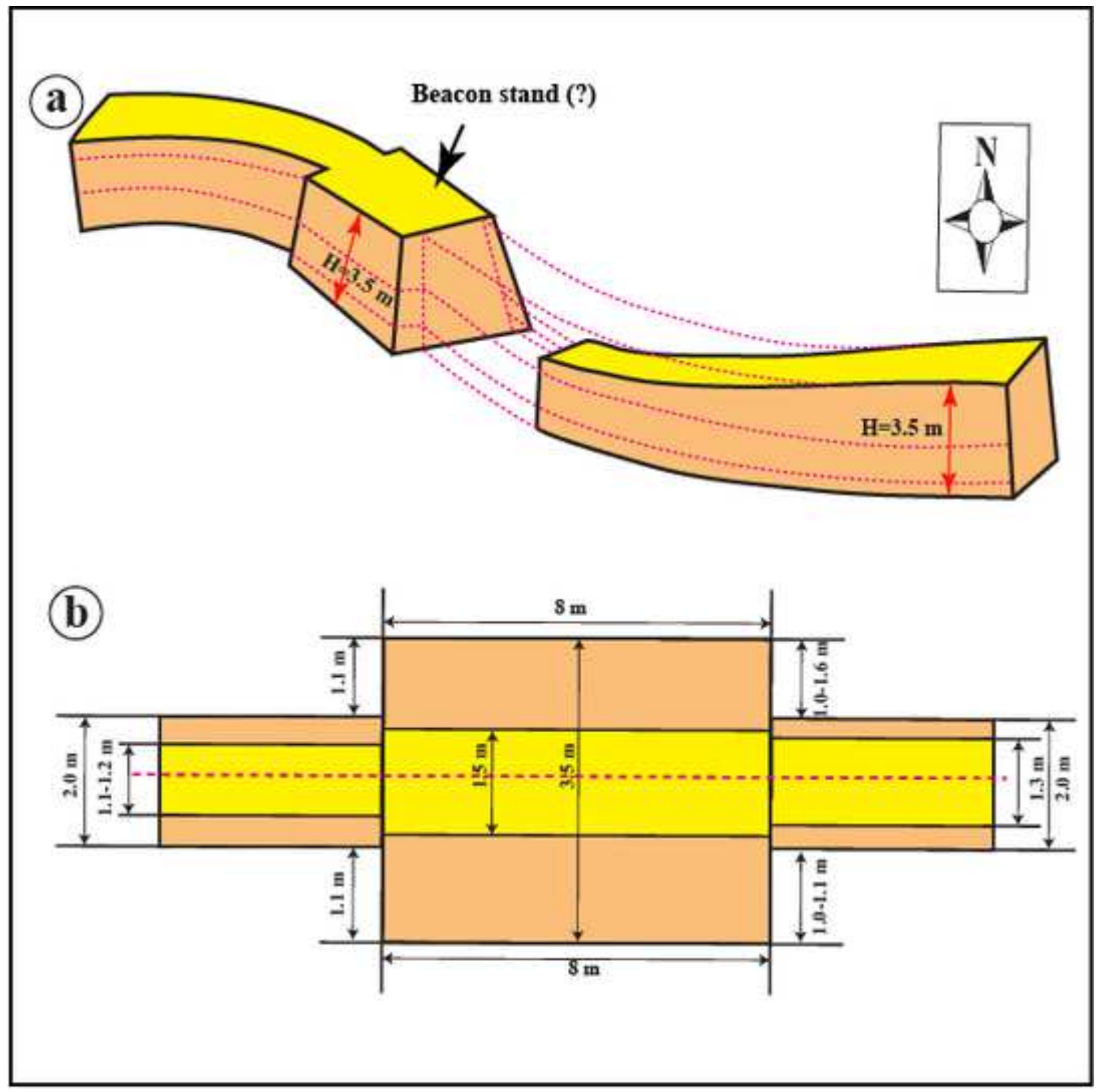



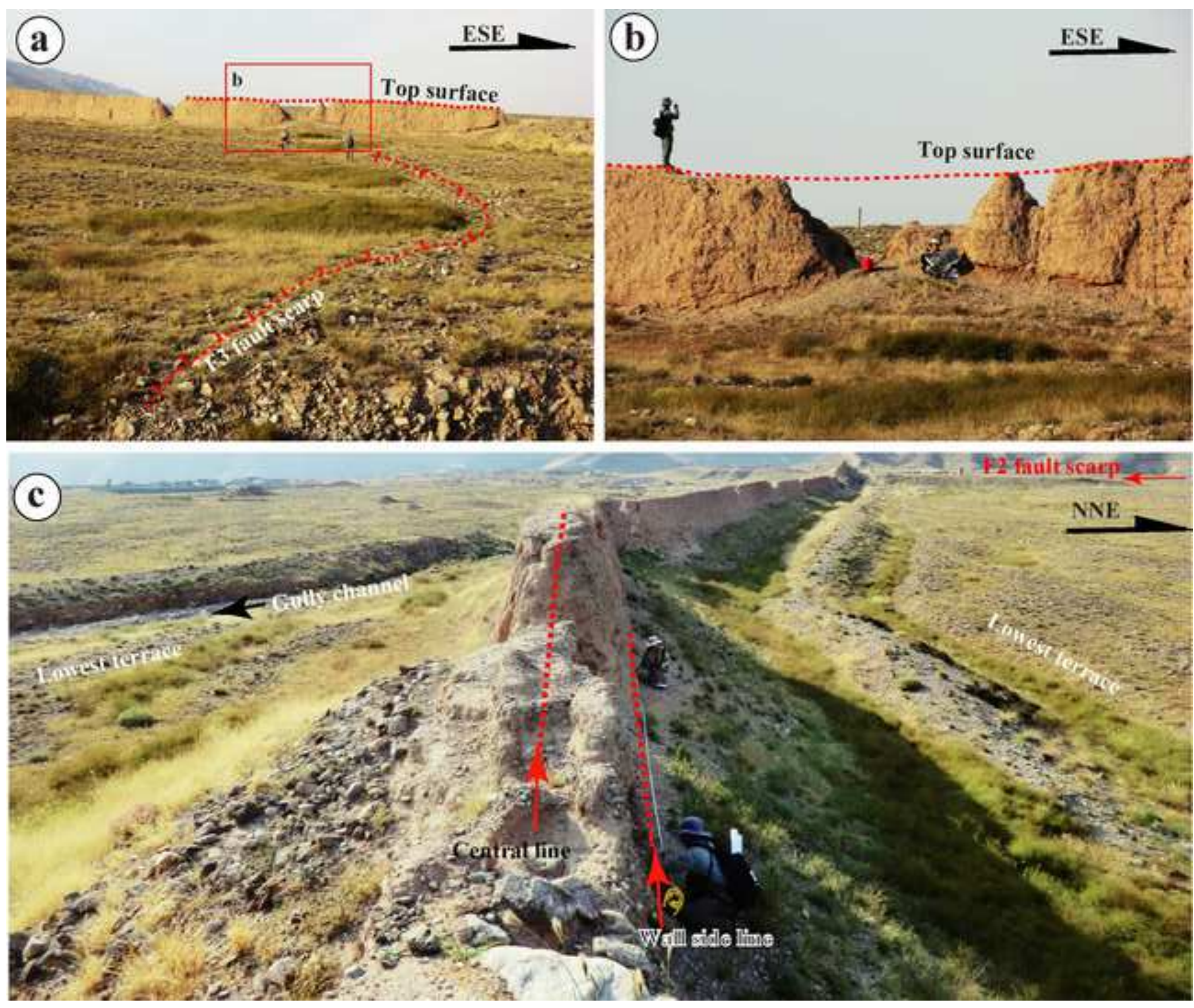